Pacific Journal of Mathematics

SOME EXAMPLES FOR THE FIXED POINT PROPERTY 


\title{
SOME EXAMPLES FOR THE FIXED POINT PROPERTY
}

\author{
GLEN E. BREDON
}

\begin{abstract}
Examples are given of polyhedra $K$ and $L$ which have the homotopy invariant fixed point property, in the sense that all polyhedra of the same homotopy type have the fixed point property (in fact $K$ and $L$ have no self-maps of zero Lefschetz number) but for which $K \times L$ fails to have the fixed point property.
\end{abstract}

Examples have been constructed (see $[2,4]$ ) of polyhedra $K$ and $L$ with the fixed point property such that $K \times L$ does not have the fixed point property. However, these examples are not completely satisfactory in the sense that the fixed point property for $K$ can be lost by a minor alteration of $K$ without changing its homotopy type (such as by adding a 2-simplex along two edges). Indeed, this is crucial for the examples.

It would be of much greater interest to give examples of this phenomenon such that $K$ and $L$ have the homotopy invariant fixed point property, and this question was essentially asked by Bing [1] and Fadell [2]. We shall give the first such examples in this note.

For completeness, we note that it is known that, for instance, if $K$ is simply connected and satisfies the Shi condition (that $\operatorname{dim} K \geqq 3$ and no point of $K$ separates $K$ locally) then $K$ has the fixed point property if and only if it has no self-maps of zero Lefschetz number; see [2] for references. All the spaces we shall consider are of this type, but we shall not make use of this fact.

The spaces we shall be concerned with are the (reduced) mapping cones $C_{\varphi}=S^{n} \bigcup_{\varphi} e^{m+1}$ of maps $\varphi: S^{m} \rightarrow S^{n}$ with $m>n$. We treat them as $C W$-complexes, but they can be assumed to be triangulable. Reduced suspension is denoted by $S$. Note that $S C_{\varphi}=C_{S \varphi}$.

THeOREm A. Suppose that $\varphi: S^{m} \rightarrow S^{n}(m>n)$ is a suspension. If $m$ and $n$ have the same parity then $C_{\varphi}$ has the fixed point property if and only if $[\varphi] \neq 0$ in $\pi_{m}\left(S^{n}\right)$. If $m$ and $n$ have opposite parity, then $C_{\varphi}$ has a self-map of Lefschetz number zero if and only if $[\varphi] \in \pi_{m}\left(S^{n}\right)$ has odd order.

Proof. Let $f: C_{\varphi} \rightarrow C_{\varphi}$ and let us compute the Lefschetz number $L(f)$. We may change $f$ by a homotopy so that $f$ takes $S^{n} \subset C_{\varphi}$ into itself. Let $D$ be the image in $C_{\varphi}$, under the characteristic map, of the $(m+1)$-disk of radius $1 / 2$ in the unit disk $e^{i n+1}$. Then by a wellknown approximation argument (either simplicial or smooth), which 
we shall not give, $f$ may be again altered by a homotopy so that it satisfies the following condition: There are $(m+1)$-disks $D_{1}, D_{2}, \cdots$, $D_{r}$ in the interior of the $(m+1)$-cell of $C_{\varphi}$ such that $f$ takes each $D_{i}$ homeomorphically onto $D$ (and thus has degree \pm 1 there) and $f\left(C_{\varphi}-\cup D_{i}\right) \subset C_{\varphi}-D$. We may as well also assume that the $D_{i}$ are all inside $D$. There is the canonical deformation retraction

$$
\psi: C_{\varphi}-\operatorname{int} D \rightarrow S^{n}
$$

and we may, and shall, identify $\varphi$ with $\psi \mid \partial D$. Now let $x \in H_{n}\left(C_{\varphi}\right)$ and $y \in H_{m+1}\left(C_{\varphi}\right)$ be generators. Let

$$
f_{*}(x)=j x \text { and } f_{*}(y)=k y \text {. }
$$

Then $j=\operatorname{deg} f_{1}$ where $f_{1}: S^{n} \rightarrow S^{n}$ is the restriction of $f$. Also $k$ is the sum of the degrees (each \pm 1 ) of $f$ on the $D_{i}$ to $D$ (or, equivalently, of $f$ on $\partial D_{i}$ to $\partial D$ ). Let $\eta: \partial D \rightarrow C_{\varphi}$ be the inclusion and consider the composition

$$
\psi \circ f \circ \eta: \partial D \rightarrow S^{n}
$$

By the homotopy addition theorem, the homotopy class of this in $\pi_{m}\left(S^{n}\right)$ is

$$
[\psi \circ f \circ \eta]=\sum\left[\varphi \circ\left(f \mid \partial D_{i}\right)\right]=k[\varphi] .
$$

Since $\eta$ is homotopic, through $C_{\varphi}-$ int $D$, to $\varphi: \partial D \rightarrow S^{n} \subset C_{\varphi}$, we see that $\psi \circ f \circ \eta$ is homotopic to $\psi \circ f_{1} \circ \varphi=f_{1} \circ \varphi$. Thus

$$
k[\varphi]=[\psi \circ f \circ \eta]=\left[f_{1} \circ \varphi\right]=j[\varphi],
$$

with the last equality holding since $\varphi$ is a suspension. Thus we conclude that

$$
k \equiv j(\bmod \operatorname{ord}[\varphi])
$$

Now

$$
\begin{aligned}
L(f) & =1+(-1)^{n} j+(-1)^{m+1} k \\
& \equiv 1+\left[(-1)^{n}-(-1)^{m}\right] j \quad(\bmod \operatorname{ord}[\varphi]) .
\end{aligned}
$$

Thus if $L(f)=0$, then ord $[\varphi]$ divides $1+\left[(-1)^{n}-(-1)^{m}\right] j$ which is $o d d$, and hence ord $[\varphi]$ is odd. If, moreover, $n$ and $m$ have the same parity then $0=L(f) \equiv 1$ so that $[\varphi]=0$.

If $[\varphi]=0$, there is a retraction $r: C_{\varphi} \rightarrow S^{n}$. Following this by the antipodal map on $S^{n}$ and the inclusion $S^{n} \subset C_{\varphi}$ gives a fixed point free map on $C_{\varphi}$.

Suppose now that $n$ and $m$ have opposite parity and that $p=$ $\operatorname{ord}[\varphi]$ is odd. For sake of simplicity of argument, let us suppose that $n$ is even and $m$ is odd. Then define $j$ by $p=1+2 j$ and put 
$k=-(1+j)$ so that $j-k=p$. Let $j: S^{n} \rightarrow S^{n}$ and $k: S^{m} \rightarrow S^{m}$ also stand for maps of degrees $j$ and $k$ respectively. Since $[\varphi \circ k]=k[\varphi]=$ $j[\varphi]=[j \circ \varphi]$ it follows easily that there is a map $g$ of the mapping cylinder $M_{\varphi} \rightarrow M_{\varphi}$ which is $k$ on the top face $S^{m}$ and is $j$ on the bottom face $S^{n}$. Let $f: C_{\varphi} \rightarrow C_{\varphi}$ be the union of $g$ with the cone on the map $k$. Then $L(f)=1+j+k=0$ as desired.

Many cases of nonpreservation of the fixed point property under suspension follow from Theorem A. Perhaps the most interesting ones are the following:

THEOREM B. Let $K$ be the spase obtained from $S^{k} \times S^{k}$ by identifying $\left(x_{0}, x\right)$ with $\left(x, x_{0}\right)$ for some fixed $x_{0}$ and all $x$. (Thus $K=C_{\varphi}$ for a map $\varphi: S^{2 k-1} \rightarrow S^{k}$ representing the Whitehead product [e, e] where $e \in \pi_{k}\left(S^{k}\right)$ is the class of the identity.) Then for $k \neq 1,3,7, K$ has the fixed point property but $S K$ does not.

Proof. $S K=C_{S \varphi}$ and $[S \varphi]=S[e, e]=0$, as is well-known. (See [3] or [5; pp. 488-502] and note that $\varphi=\alpha_{k}$ in the latter reference.) Thus $S K$ admits a map without fixed points as noted in the proof of Theorem A. Moreover, $[e, e]=0$ only for $k=1,3,7$ since these are the only spheres which are $H$-spaces. If $k$ is odd, then the suspension $\pi_{2 k-2}\left(S^{k-1}\right) \rightarrow \pi_{2 k-1}\left(S^{k}\right)$ is onto by [5; pp. 489-501] so that the result follows from Theorem A. Suppose now that $k$ is even. Then the Hopf invariant of $\varphi$ is 2 (see [3; p. 336] or [5; pp. 488-502]). Thus if $x \in H^{k}(K)$ and $y \in H^{2 k}(K)$ are suitable generators we have that $x^{2}=2 y$. If $f: K \rightarrow K$ has $f^{*}(x)=n x$, then

$$
2 f^{*}(y)=f^{*}(2 y)=f^{*}\left(x^{2}\right)=f^{*}(x)^{2}=(n x)^{2}=2 n^{2} y \text {. }
$$

Thus the Lefschetz number

$$
L(f)=1+n+n^{2} \neq 0
$$

since $n$ is an integer.

Now we come to the main result of this note. See the remarks following the proof for specific instances for which the hypotheses are satisfied.

THeOREM C. Let $n$ be odd and let $k$ and $l$ be even. Let $[\varphi] \in \pi_{n+k}\left(S^{n}\right)$ and $[\psi] \in \pi_{n+l}\left(S^{n}\right)$ be nonzero suspensions of orders $p$ and $q$ respectively. Suppose that $p$ and $q$ are relatively prime. Then $K=C_{\varphi}$ and $L=C_{\psi}$ both have the (homotopy invariant) fixed point property, but $K \times L$ has fixed point free self-maps.

Proof. $K$ and $L$ have the fixed point property by Theorem A. At least one, say $q$, of $p$ and $q$ is odd. Then we can find integers 
$a$ and $b$ such that

$$
2 a p+b q=1 \text {. }
$$

Since a map $S^{n} \rightarrow S^{n}$ of degree ap kills $[\varphi]$, it extends to $K=G_{\varphi}$. That is, there is a map $f: K \rightarrow S^{n}$ which has degree $a p$ on $S^{n} \rightarrow S^{n}$. Similarly, there is a map $g: L \rightarrow S^{n}$ which has degree $b q$ on $S^{n}$. Let $x \in H_{n}\left(S^{n}\right)$ be a generator. Since $n$ is odd there exists a map $\tau: S^{n} \times$ $S^{n} \rightarrow S^{n}$ of bidegree $(2,1)$; see [6; p. 14]. That is, $\tau_{*}$ takes $x \times 1$ to $2 x$ and takes $1 \times x$ to $x$. Let $\Delta: S^{n} \rightarrow K \times L$ be the diagonal $S^{n} \rightarrow$ $S^{n} \times S^{n}$ followed by inculsion, and note that $\Delta_{*}(x)=x \times 1+1 \times x$.

Consider the composition $\Delta \circ \tau \circ(f \times g): K \times L \rightarrow K \times L$, whose image is in $S^{n}$ considered as the diagonal in $S^{n} \times S^{n} \subset K \times L$. The restriction of $\tau \circ(f \times g)$ to the diagonal $S^{n} \rightarrow S^{n}$ is just $\tau \circ(f \times g) \circ \Delta$ which, in homology, takes $x$ to $2 a p x+b q x=x$. Thus $\tau \circ(f \times g) \circ \Delta$ has degree one and, since $n$ is odd, is homotopic to a fixed point free map. By the homotopy extension theorem, $\tau \circ(f \times g): K \times L \rightarrow S^{n}$ is homotopic to a map $\mu: K \times L \rightarrow S^{n}$ whose restriction to the diagonal $S^{n}$ has no fixed points. Then $\Delta \circ \tau \circ(f \times g)$ is homotopic to $\Delta \circ \mu: K \times$ $L \rightarrow K \times L$. Now $\Delta \circ \mu$ has no fixed points since it has none on the diagonal $S^{n}$ and its image is in $S^{n}$. This completes the proof. (Alternatively, one could compute directly that $\Delta \circ \tau \circ(f \times g)$ has zero Lefschetz number and use known results which imply that this must be homotopic to a fixed point free map, since $K \times L$ is simply connected and satisfies the Shi condition.)

REMARKS. (1) Although such homotopy classes probably exist in profusion, they are not easy to find. The only stable class $[\psi] \epsilon$ $\pi_{n+l}\left(S^{n}\right), l$ even, of odd order appearing in toda's tables [7; p. 186] is for $l=10$. However, many more cases can be found in his tables in [8]. Of course, classes of even order abound.

(2) Taking $n \geqq 13$ and odd, there are examples with both [ $\varphi$ ] and $[\psi]$ in the stable group $\pi_{n+10}\left(S^{n}\right) \approx Z_{6}$; see [7].

(3) The example in the least dimension seems to be $[\varphi] \in \pi_{9}\left(S^{7}\right)$ of order 2 and $[\psi] \in \pi_{17}\left(S^{7}\right)$ of order 3 (which is a suspension since $S: \pi_{16}\left(S^{2}\right) \rightarrow \pi_{17}\left(S^{7}\right)$ is onto).

(4) In the case $n=7$ one could use Cayley multiplication, having bidegree $(1,1)$, rather than $\tau$.

(5) It is of interest to note that the fixed point free map $\Delta \circ \mu$ : $K \times L \rightarrow K \times L$ can be so chosen that none of its iterates has fixed points.

(6) We believe that our examples show that failure for the fixed point property to be preserved by suspensions and products should be regarded as a normal phenomenon.

(7) I have been told that W. Holsztynski also noticed that 
mapping cones give examples of the nonpreservation of the fixed point property under suspension.

\section{REFERENCES}

1. R. H. Bing, The elusive fixed point property, Amer. Math. Monthly, 76 (1969), 119132.

2. E. Fadell, Recent results in the fixed point theory of continuous maps, Bull. Amer. Math. Soc., 76 (1970), 10-29.

3. S.-T. Hu, Homotopy Theory, Academic Press, New York (1959).

4. W. Lopes, An example in the fixed point theory of polyhedra, Bull. Amer. Math. Soc., 73 (1967), 922-924.

5. E. H. Spanier, Algebraic Topology, McGraw-Hill, New York (1966).

6. N. E. Steenrod and D. B. A. Epstein, Cohomology Operations, Annals of Math. Studies, No. 50, Princeton Univ. Press, (1962).

7. H. Toda, Composition Methods in Homotopy Groups of Spheres, Annals of Math. Studies, No. 49, Princeton Univ. Press (1962).

8. - p-primary components of homotopy groups. III. Stable groups of the sphere. Mem. Coll. Sci. Univ. Kyoto. Ser. A. Math., 31 (1958), 191-210.

Received May 29, 1970. This research was supported in part by NSF Grant GP-11468.

RUTGERS UNIVERSITY 



\title{
PACIFIC JOURNAL OF MATHEMATICS
}

\author{
EDITORS
}

\author{
H. Samelson \\ Stanford University \\ Stanford, California 94305 \\ C. R. HOBBY \\ University of Washington \\ Seattle, Washington 98105
}

J. DugundJI

Department of Mathematics

University of Southern California

Los Angeles, California 90007

RICHARD ARENS

University of California

Los Angeles, California 90024

\section{ASSOCIATE EDITORS}

E. F. BECKENBACH
B. H. NEUMANN

F. WoLF
K. YosHIDA

\section{SUPPORTING INSTITUTIONS}

\author{
UNIVERSITY OF BRITISH COLUMBIA \\ CALIFORNIA INSTITUTE OF TECHNOLOGY \\ UNIVERSITY OF CALIFORNIA \\ MONTANA STATE UNIVERSITY \\ UNIVERSITY OF NEVADA \\ NEW MEXICO STATE UNIVERSITY \\ OREGON STATE UNIVERSITY \\ UNIVERSITY OF OREGON \\ OSAKA UNIVERSITY \\ UNIVERSITY OF SOUTHERN CALIFORNIA
}

\author{
STANFORD UNIVERSITY \\ UNIVERSITY OF TOKYO \\ UNIVERSITY OF UTAH \\ WASHINGTON STATE UNIVERSITY \\ UNIVERSITY OF WASHINGTON \\ $\stackrel{*}{*} \stackrel{*}{*} \stackrel{*}{*}{ }^{*}{ }^{*}$ MERICAN MATHEMATICAL SOCIETY \\ CHEVRON RESEARCH CORPORATION \\ NAVAL WEAPONS CENTER
}

The Supporting Institutions listed above contribute to the cost of publication of this Journal, but they are not owners or publishers and have no responsibility for its content or policies.

Mathematical papers intended for publication in the Pacific Journal of Mathematics should be in typed form or offset-reproduced, (not dittoed), double spaced with large margins. Underline Greek letters in red, German in green, and script in blue. The first paragraph or two must be capable of being used separately as a synopsis of the entire paper. The editorial "we" must not be used in the synopsis, and items of the bibliography should not be cited there unless absolutely necessary, in which case they must be identified by author and Journal, rather than by item number. Manuscripts, in duplicate if possible, may be sent to any one of the four editors. Please classify according to the scheme of Math. Rev. Index to Vol. 39. All other communications to the editors should be addressed to the managing editor, Richard Arens, University of California, Los Angeles, California, 90024.

50 reprints are provided free for each article; additional copies may be obtained at cost in multiples of 50 .

The Pacific Journal of Mathematics is published monthly. Effective with Volume 16 the price per volume (3 numbers) is $\$ 8.00$; single issues, $\$ 3.00$. Special price for current issues to individual faculty members of supporting institutions and to individual members of the American Mathematical Society: $\$ 4.00$ per volume; single issues $\$ 1.50$. Back numbers are available.

Subscriptions, orders for back numbers, and changes of address should be sent to Pacific Journal of Mathematics, 103 Highland Boulevard, Berkeley, California, 94708.

PUBLISHED BY PACIFIC JOURNAL OF MATHEMATICS, A NON-PROFIT CORPORATION

Printed at Kokusai Bunken Insatsusha (International Academic Printing Co., Ltd.), 7-17, Fujimi 2-chome, Chiyoda-ku, Tokyo, Japan. 


\section{Pacific Journal of Mathematics}

J. T. Borrego, Haskell Cohen and Esmond Ernest Devun, Uniquely

representable semigroups on the two-cell .................. 565

Glen Eugene Bredon, Some examples for the fixed point property ........ 571

William Lee Bynum, Characterizations of uniform convexity .......... 577

Douglas Derry, The convex hulls of the vertices of a polygon of order $n \ldots 583$

Edwin Duda and Jack Warren Smith, Reflexive open mappings .......... 597

Y. K. Feng and M. V. Subba Rao, On the density of $(k, r)$ integers ........ 613

Irving Leonard Glicksberg and Ingemar Wik, Multipliers of quotients of

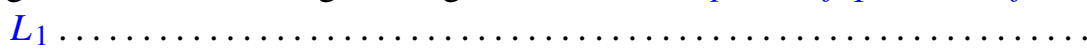

John William Green, Separating certain plane-like spaces by Peano

continua.........................................

Lawrence Albert Harris, A continuous form of Schwarz's lemma in normed

linear spaces .................................... 635

Richard Earl Hodel, Moore spaces and $w$-spaces ............... 641

Lawrence Stanislaus Husch, Jr., Homotopy groups of PL-embedding spaces.

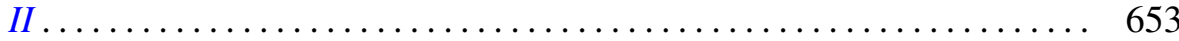

Yoshinori Isomichi, New concepts in the theory of topological

space-supercondensed set, subcondensed set, and condensed set.....

J. E. Kerlin, On algebra actions on a group algebra .................

669

Keizō Kikuchi, Canonical domains and their geometry in $C^{n} \ldots \ldots \ldots \ldots 681$

Ralph David McWilliams, On iterated $w^{*}$-sequential closure of cones. .

697

C. Robert Miers, Lie homomorphisms of operator algebras ..

717

Louise Elizabeth Moser, Elementary surgery along a torus knot ...

737

Hiroshi Onose, Oscillatory properties of solutions of even order differential

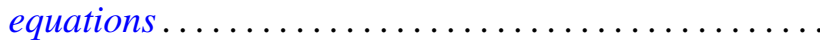

747

Wellington Ham Ow, Wiener's compactification and $\Phi$-bounded harmonic

functions in the classification of harmonic spaces...

Zalman Rubinstein, On the multivalence of a class of meromorphic

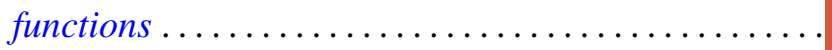

771

785

Hans H. Storrer, Rational extensions of modules

795

topological lattices ...........................

Robert Evert Stong, On the cobordism of pairs .................. 803
Albert Leon Whiteman, An infinite family of skew Hadamard matrices . . . 817

Lynn Roy Williams, Generalized Hausdorff-Young inequalities and mixed

norm spaces 